\title{
Immune Response Among the Children to Hepatitis B Vaccination: A Community-based Study in Bangladesh
}

\author{
Hossain $\mathrm{MM}^{1 *}$, Alam $\mathrm{AN}^{2}$, Siddiqua $\mathrm{M}^{3}$, Siddika $\mathrm{A}^{4}$, Afzalunnessa ${ }^{5}$ \\ ${ }^{1}$ Department of Paediatric Neurology, Bangabandhu Sheikh Mujib Medical University, Dhaka, Bangladesh \\ ${ }^{2}$ Institute of Epidemiology, Disease Control and Research, Dhaka, Bangladesh \\ ${ }^{3}$ Department of Microbiology, Ibn Sina Medical College, Dhaka, Bangladesh \\ ${ }^{4}$ Department of Community Medicine, Mugda Medical College, Dhaka, Bangladesh \\ ${ }^{5}$ Department of Virology, Bangabandhu Sheikh Mujib Medical University, Dhaka, Bangladesh
}

\begin{abstract}
Hepatitis B virus infection is a vaccine preventable infection of liver which remains a key public health burden globally. The development of Anti-HBs titre greater than or equal to $10 \mathrm{IU} / \mathrm{L}$ is considered as protective immunity and any titre less than $10 \mathrm{IU} / \mathrm{L}$ as non-protective following $\mathrm{HBV}$ vaccination. There is no comprehensive and authentic data regarding the immune response even 10 years after the integration of the HBV vaccine in to the EPI programme in Bangladesh and specifically, in Brahmonbaria district. The study was also aimed to assess the long term immune response among HBV vaccinated children. Blood sample from 500 vaccinated children were tested for Anti-HBs, and anti-HBc. Sero negative children were given 1 dose of HBV vaccine as a booster. Samples from booster vaccine were taken one month later and tested for anti Hbs titre. Anti HBs titre was found below protective level in about 46.0\% (230/500) participants. Sero-protection rate decreased to $72.2 \%$ in 5 to 6 years age group which further decreased to $58.3 \%$ in 7 to 9 years age group and increased again to $69.5 \%$ in 10 to 12 years age group children. On the other hand, the mean anti Hbs titre was $97.72 \mathrm{IU} / \mathrm{L}$ initially and then increased with the increasing of age from 165.40 IU/L to $196.67 \mathrm{IU} / \mathrm{L}$. Breakthrough infection of HBV was seen in $1.2 \%$ (6/500) participants measuring by anti HBc which indicated protective efficacy of HBV vaccine was about $98.8 \%(494 / 500)$. Sero negative participants were given a booster dose; $93.6 \%$ (131/140) participants showed boosting of mean anti HBs titre upto $804.92 \mathrm{IU} / \mathrm{L}$ which was below protective level $(<10 \mathrm{IU} / \mathrm{L})$ before booster dose. Anti-HBs titre goes below with the increase of age after vaccination. Most of the participants had immunological memory which will boost antibody titre after any exposure, so routine booster dose is not needed. But non-responder to vaccination should screen after primary vaccination because of chance of breakthrough infection.
\end{abstract}

Keywords: Hepatitis B Virus, Immune response, Antibody titre

\section{Introduction}

Hepatitis B virus infection is a vaccine preventable infection of liver which remains a key public health burden globally. It is estimated that 2 billion individuals have been infected with Hepatitis B virus of which 350 million have become chronically infected and each year 4 million new acute infections occur. ${ }^{1}$ Hepatitis B virus infection causes more than $50.0 \%$ of all cases of hepatocellular carcinoma and approximately 600,000 deaths per annum. ${ }^{2}$ One of the principal factors that influence the incidence and occurrence of the chronic carriage status is the age at which Hepatitis B virus infection occurs. Approximately $90.0 \%$ of babies born to HBV surface antigen(HBsAg) and hepatitis B e antigen ( $\mathrm{HBeAg}$ )- positive mothers and about $30.0 \%$ of children infected before 6 years of age become chronic carriers, which is less than $10.0 \%$ in case of adults or grown-up children. ${ }^{3,4}$

The most effective way of controlling hepatitis B infection is by immunization. The development of Anti-HBs titre greater than or equal to $10 \mathrm{IU} / \mathrm{L}$ is considered as protective immunity and any titre less than $10 \mathrm{IU} / \mathrm{L}$ as non-protective following HBV vaccination..$^{5}$ According to World Health Organization, 177 countries have incorporated the Hepatitis B virus vaccine into their Expanded Programme on Immunization (EPI) by $2008 .{ }^{6}$ In Bangladesh, the penta-valent, diphtheria-pertussistetanus (DPT), hepatitis B (HBV), and Haemophilus influenza type b (Hib) vaccine was 
incorporated into EPI program while maintaining the immunization schedule at 6,10 and 14 weeks after birth in 2009 as recommended by the WHO.

In spite of the availability of a vaccine, and recommendation by WHO to screen pregnant women for $\mathrm{HBsAg}$ to provide appropriate immunization for the babies of positive mothers, $\mathrm{HBV}$ infection persists worldwide.

There is no comprehensive and authentic data regarding the prevalence of Hepatitis B infection and the sero-protective rate of the vaccine 10 years after the integration of the HBV vaccine in to the EPI programme in Bangladesh and specifically, in Brahmonbaria district.

Post vaccination testing for antibody titre within 16 months after completion of vaccination schedule is recommended to detect nonresponders. Although antibody titres decline, it should be reasonably greater than $10 \mathrm{IU} / \mathrm{L}$ at any time in order to ensure immune protection among vaccinated people. ${ }^{7}$ No such surveillance has been conducted hence there is no evidence or data regarding the prevalence of $\mathrm{HBV}$, the effectiveness of the vaccine, the seroprotection rate and duration of immunity among recipients of the vaccine in Bangladesh. This study seeks to determine long term immune response to $\mathrm{HBV}$ vaccination hence prevalence of $\mathrm{HBV}$ among the vaccinated children, also to evaluate the effectiveness of the vaccine, the seroprotection rate and duration of immunity among recipients of the EPI vaccine 5-12 years after completion of their primary vaccination schedule.

\section{Martial and Methods}

This was a cross sectional study conducted from January 2016 to June 2017 involving 500 healthy or asymptomatically healthy children of the Brahmonbaria district, Bangladesh. They completed the HBV vaccine in EPI programme 512 years ago and born after the integration of the HBV vaccine in EPI program in 2003. Written informed consent was obtained from the legal guardians of the participants before samples were collected. The infant immunization records of the vaccinated group were inspected to ascertain whether all 3 doses of the HBV vaccine had been duly completed. Only children who met this criterion were included in the vaccinated group.
Three $\mathrm{ml}$ of blood sample was taken from anticubital vein with full aseptic precaution from each child. Serum was separated from blood samples at collection place. Sample was stored at $-20{ }^{0} \mathrm{C}$ temperatures until transported to virology laboratory, Bangabandu Sheikh Mujab Medical University (BSMMU) and all the laboratory works were done there.

Among them, 230 children whose anti Hbs level was less than 10IU/L further recalled for taking one booster dose for Hepatitis B vaccine. Of them 153 children came to take booster dose. Out of them, 140 children were finally attended to study place for giving blood sample after one month. Then 140 samples were stored and sent to virology laboratory BSMMU for anti HBs testing.

Anti-HBs assay were done by using Chemiluminescent immunoassay (CLIA) technology for the quantitative determination of antibody to hepatitis B surface antigen (Anti-HBs) in human serum or plasma samples. ${ }^{8}$ The Detection of hepatitis B Virus core antibody $(\mathrm{HBcAb})$ Test Kit is a rapid and convenient immune chromatographic in vitro assay for detection of $\mathrm{HBcAb}$ in human serum or plasma. This kit provide a visual, qualitative result. ${ }^{9}$ The study protocol was approved by the Ethical Committee on Human Research Publications and Ethics, the Institutional Review Board (IRB) of Ibn Sina Medical College, Dhaka. Statistical analysis was performed using SPSS software.

\section{Results}

Out of the 500 participants, $38.0 \%$ (190/500) were females while $62.0 \%$ (310/500) were males. All the participants were divided into three age group which included 'Group A' 5 to 6 years old children, 7 to 9 years were 'Group B' and 10 to 12 years were 'Group C'. Among these three age groups 132 (26.4\%) subjects were from Group A, $220(44.0 \%)$ were from Group B, and 148 (29.6\%) were from Group C. (table I)

Table I: Gender and age distribution among the study population

\begin{tabular}{lcc}
\hline \multicolumn{1}{c}{ Features } & Frequency & Percent \\
\hline Gender distribution & 190 & \\
Female & 310 & 38 \\
Male & & 62 \\
Age Category & 132 & \\
Group A (5 -6 years) & 220 & 26.4 \\
Group B (7 - 9 years) & 148 & 44.0 \\
Group C (10 - 12 years) & & 29.6 \\
\hline
\end{tabular}


Anti-HBs titre among the participants were divided as 'No protection' if antibody titre was below 10 IU/L, 'moderate protection' if the titre is between 10 to $100 \mathrm{IU} / \mathrm{L}$ and as 'strong protection' if titre is more than $100 \mathrm{IU} / \mathrm{L}$.Figure 1 shows, among the participants $46.0 \%(230 / 500)$ had titre below protection level, 36.4\% (182/500) had moderate protection and only 17.6 (88/500) had strong protection (figure 1).

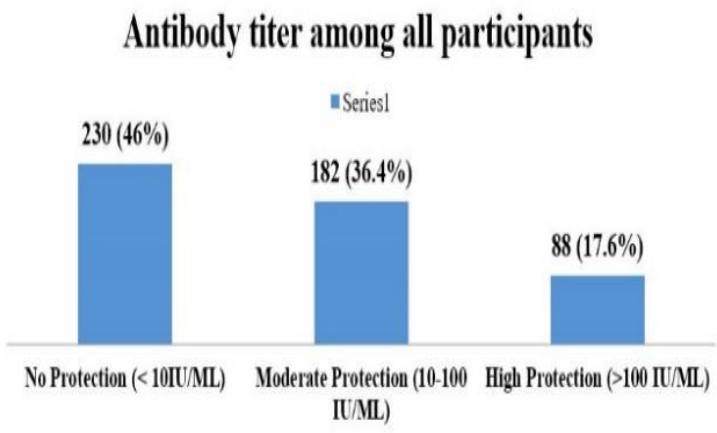

Figure 1

Mean Anti-HBs antibody titre among seropositive male and female participants (anti $\mathrm{HBs}>10 \mathrm{IU} / \mathrm{L}$ ) were found $190.00 \mathrm{IU} / \mathrm{L}$ and $106.93 \mathrm{IU} / \mathrm{L}$ and this difference was statistically significant. AntiHBsmean titre among the seropositive participants was found $97.72 \mathrm{IU} / \mathrm{L}, 165.40 \mathrm{IU} / \mathrm{L}$, and 196.67 IU/L in Group A, B and C participants respectively. These differences were also statistically significant. (table II)

Table II: Mean antibody titre difference seropositive (Anti HBs > 10 IU/L) Children

\begin{tabular}{lccc}
\hline \multicolumn{5}{c}{$\begin{array}{c}\text { Mean Antibody titre according to gender distribution } \\
\text { Sex }\end{array}$} & n & Mean Anti HBs titre (range) & $\boldsymbol{p}$ value \\
\hline Female & 106 & 106.9321 & \\
& & $(\mathrm{SD} \pm 173.93681)$ & 0.004 \\
Male & 164 & 190.0085 & $(\mathrm{SD} \pm 298.99036)$ \\
& \multicolumn{4}{c}{$\begin{array}{l}\text { Mean Antibody } \\
\text { Age group }\end{array}$} & $\mathrm{N}$ & Mean Anti HBs titre (range) & $p$ value \\
$\begin{array}{l}\text { Group A (5-6 } \\
\text { years) }\end{array}$ & 68 & 97.7250 & \\
$\begin{array}{l}\text { Group B (7-9 } \\
\text { years) }\end{array}$ & 124 & 165.4048 & 0.021 \\
$\begin{array}{l}\text { Group C (10- } \\
\text { 12 years) } \\
\text { Total }\end{array}$ & 78 & 196.6756 & \\
\hline & 270 & 157.3933 & \\
\hline
\end{tabular}

Among the 140 children vaccinated with booster dose who had anti HBs below protection level $(<$ $10 \mathrm{IU} / \mathrm{L}), 9$ subjects did not show any response to booster dose. Among the rest of the 131children who have responded to booster dose antibody titre was seen after one month and mean Anti-HBswas found $804.92 \mathrm{IU} / \mathrm{L}$ which ranged from minimum
$11.90 \mathrm{IU} / \mathrm{L}$ to maximum > $1000 \mathrm{IU} / \mathrm{L}$ (table $\mathrm{III}$ ). This difference was statistically significant.

Table III: Antibody titre among participants before and after giving booster dose $(\mathrm{n}=131)$

\begin{tabular}{cccccc}
\hline & n & Minimum & Maximum & Mean & $\begin{array}{c}p \\
\text { value }\end{array}$ \\
\hline $\begin{array}{c}\text { Anti-HBs } \\
\text { titre before } \\
\text { booster dose } \\
\begin{array}{c}\text { Anti-HBs } \\
\text { titre after } \\
\text { booster dose }\end{array}\end{array}$ & 131 & 5 & 9.9 & 5.89 & \\
\hline
\end{tabular}

\section{Discussion}

The present study was designed to evaluated seroconversion and seroprotection status by measuring the Anti-HBs titre among the individuals of different age and sex, vaccinated in EPI schedule 5 to 12 years after vaccination. One but all children showed levels of seroconversion (i.e. had Anti-HBs $\geq 1 \mathrm{IU} / \mathrm{L}$ ) after three doses of hepatitis $\mathrm{B}$ vaccination and indicated seroconversion rate was $99.9 \%$. A study conducted in Bangladesh among EPI-vaccinated children, showed the rate of sero-conversion was $92.2 \% .{ }^{10}$ The present study is consistent with a longitudinal study by Freitas da Motta et al., in Brazil, ${ }^{11}$ who reported, $98.0 \%$ of individuals seroconverted. Moreover, Chakraborty et al reported $100.0 \%$ seroconversion in a cross-sectional study in Bangladesh. $^{12}$

Some of the antibody levels however, did not reach a concentration that confers protection (< $10 \mathrm{IU} / \mathrm{L}$ ). Out of 500 vaccinated persons, who received 3 doses of Hepatitis $B$ vaccine, 270 developed seroconversion with protective level of immunity in the current study. The overall seroprotectivity rate (Anti-HBs titre $>10 \mathrm{IU} / \mathrm{L}$ ) among the vaccinated individuals was found to be $54.0 \%$.

In the present study prevalence of HBV infection was confirmed by detecting anti $\mathrm{Hbc}$ among vaccinated children that should not be present if protection is adequate by vaccination. The prevalence of HBV infection among general population found in different previous studies in Bangladesh was about 5.5\%, 5.4\%, 4.4\%, and $3.0 \% .{ }^{13-16}$ In this study, among the vaccinated 500 children only 6children were found to have anti $\mathrm{Hbc}$ in serum indicating breakthrough infection which was about only in $1.2 \%$ (6/500). This 
significant decrease in HBV infection among the vaccinated children might be as a result of the effectiveness of the HBV infant immunization in preventing the horizontal transmission of the virus to the vaccinated children. In one case, who was positive for anti $\mathrm{Hbc}$, was positive for $\mathrm{HBsAg}$ also. Mother of that child was tested and found positive for $\mathrm{HBsAg}$ which indicated vertical transmission of HBV to child.

In this study, it was evident that across age groups seroprotection rate was found $51.5 \%$ at 5 to 6 years age group after which it increased up to $56.4 \%$ with increasing age among 7 to 9 years age group and then declining again with increasing age through 10 to 12 years age group up to $52.7 \%$ among the vaccinated children; but this findings was not supported by the mean Anti-HBs titre (GMT) levels which was found gradually increasing with age including $97.7 \mathrm{IU} / \mathrm{L} 5$ to 6 years age group then increased up to $165.4 \mathrm{IU} / \mathrm{L}$ and $196.7 \mathrm{IU} / \mathrm{L}$ among 7 to 9 years and 10 to 12 years age group respectively. This decline in seroprotection rates and increase in anti HBs levels in this study with increasing age from 5 to 6 years, 7 to 9 years and 10 to 12 years age group is in line with findings by Issaka Koray. ${ }^{17}$ In contrast to the overall generally low anti HBs levels among the vaccinated group can be attributed to waning immunity with increasing age, (declining AntiHBstitre values with age). The findings in this study and the findings by Lee P I et al 1995 and Lin et al 2003 showed that although the vaccination program has been very successful in reducing carriage rate of $\mathrm{HBV}$ in the world, a gradual yearly decline in antibody titres against the HBsAg among vaccinees has been noted in several follow-up studies. ${ }^{18-19}$

Sero-protections rates in the present study were found to decrease with increasing age at 5 to 6 years, which then increase in 7-9 years group and decline again among 10 to 12 year old children. This remarkable decrease and increase pattern in sero-protection rates with increasing age was supported by increasing GMT values, from 97.7 IU/L to $196.7 \mathrm{IU} / \mathrm{L}$. This finding could be the result of an anamnestic response of the older vaccinated children following recent exposure to the virus. This might especially account for the reason why younger vaccinated children rather recorded low anti- HBs levels and older children rather recorded high Anti-HBs levels. Therefore one might conclude that even though most of the children in the vaccinated group have very low anti- HBs levels, they have intact immune memory that recognizes and stimulates the production of Anti-HBs upon exposure to the virus. Hence the 230 children in this study with Anti-HBstitres $<10$ IU/L might not necessarily be non-responders to the pentavalent vaccine; they probably originally responded to the primary course of vaccination, but Anti-HBs titres have declined over the years to lower levels and this is probably what accounted for the significantly low anti HBs levels and the sero-protection rate.

Mean antibody titre of Anti HBs among male and female among the participants who were seropositive (anti $\mathrm{HBs}>10 \mathrm{IU} / \mathrm{L}$ ) were found $190.00 \mathrm{IU} / \mathrm{L}$ and $106.93 \mathrm{IU} / \mathrm{L}$. There were gender differences in the immunological response to hepatitis B vaccine among our study group and this difference was statistically significant. The findings of this current study is consistent with a study which reported that males retain higher AntiHBs Abtitres values than females. ${ }^{20}$ In contrast to our findings, the report of some studies which had reported that there was no gender differences in the immunological response to hepatitis B vaccine. ${ }^{21}$, ${ }^{22}$ In our study, response to booster dose among children who were sero-negative $(n=140)$ seen to responsive in $131(93.6 \%)$ cases and $6.5 \%$ cases were non responsive. In contrast to our study, Lu et al reported $29.2 \%$ non-responsiveness to a booster dose by vaccinees that initially seroconverted with non-protective levels. ${ }^{23}$ The need for booster dose for long term protection into adolescence and adulthood need to be well investigated and a consensus reached on them large pool of non-responders being reported across the globe.

Finally, it is recommended that, along with EPI vaccination programme in Bangladesh, all high risk groups and prospective mothers should receive $\mathrm{HB}$ vaccine in order to achieve the commendable success in $\mathrm{HB}$ vaccination for.

\section{Conclusion}

It was found out that the prevalence of Hepatitis measured by Anti-HBc positivity among children 
between the ages of 5 and 12 years who had received the $\mathrm{HBV}$ vaccine in EPI program was $1.2 \%$ in Brahmanbaria district against the background of $3.0 \%$ to $6.3 \%$ among general population who didn't take vaccine against HBV. Hence the incorporation of the HBV vaccine in the EPI in Brahmanbaria district has succeeded in reducing the prevalence of the virus from moderate endemicity to low endemicity. Routine booster dose is not recommended as most of the participants had immunological memory which will boost antibody titre after any exposure.

\section{Acknowledgement}

We acknowledged Ministry of Science and Technology, Government of the People's Republic of Bangladesh for funding this study.

Conflict of interest: Nothing to declare

\section{Reference}

1. Lavanchy D. Worldwide epidemiology of HBV infection, disease burden, and vaccine prevention. J ClinVirol. 2005; 34(Suppl 1):1-3.

2. Williams, R. "Global challenges in liver disease". Hepatology (Baltimore, Md.). 2006;44: 521-26.

3. Hyams KC. Risks of chronicity following acute hepatitis B virus infection: a review. Clin Infect Dis. 1995;20:992-1000.

4. Ip, H. M. H., Lelie, P. N., Wong, V. C. W., Kuhns, M. C. \& Reesink, H. W. Prevention of hepatitis B virus carrier state in infants according to maternal serum levels of HBV DNA. Lancet. 1989; 1:406-10.

5. Mahoney FJ, Lawrence M, Scott C, Continuing risk for hepatitis B virus transmission among Southeast Asian infants in Louisiana. Pediatrics. 1995; 96:1113-16.

6. WHO Position paper on Hepatitis B vaccines. http://www.who.int/wer/2009/wer8440.pdf

7. Viral Hepatitis Prevention Board. Antwerp VHPB Report. Editorial. Control of viral hepatitis in Europe. 1996

8. LIAISON® Anti-HBs (310120),www.diasorin.com

9. Detection of hepatitis B Virus core antibody $(\mathrm{HBcAb})$ Test Kit. www.omchcare.com

10. Khan TM. Evaluation of immnue status against hepatitis B following Hep-B vaccination under EPI programme. 2006
11. Freitas da Motta MS, Mussi-Pinhata MM, Jorge SM, Tachibana Yoshida CF, Sandoval de Souza CB Immunogenicity of hepatitis $B$ vaccine in preterm and fullterm infants vaccinated within the first week of life. Vaccine. 2002;20:1557-62.

12. Chakraborty B, Bashar T, Roy K, Noor R, Rahman MM Persistence of Anti-HBs Antibody and Immunological Memory in Healthy Individuals Vaccinated with Hepatitis B Vaccine. Stamford Journal of Microbiology. 2011;1:3741.

13. Mahtab MA, Rahman S, Karim MF, Khan M, Foster G, Solaiman S, Afroz S. Epidemiology of hepatitis $\mathrm{B}$ virus in Bangladeshi general population. Hepatobiliary Pancreat Dis Int. 2008;7:595-600

14. Shil N, Rahman A, Sultana N, Yasmin F. Markers of Hepatitis Viruses by ELISA among Healthy Blood Donors. Mymensingh Med J. 2015;24:776-79.

15. Rukunuzzaman M, Karim MB. Chronic Hepatitis B in Children - A Review. Mymensingh Med J. 2015;24:649-56

16. SU Munshi, MM Hoque, MEA Mondol, M Jalaluddin, S Tabassum, MN Islam. HBV, HCV and syphilis co-infections in human immunodeficiency virus positive Bangladeshi patients: Observation at two reference laboratories. Indian J of Microbiology. 2008;26: 3:282-83

17. Issaka Koray Nuhaila. Seroprevalence of Hepatitis B among recipients of the WHO-EPI vaccine 10 years after the integration of the Hepatitis B vaccine in to the EPI of Wa Municipality, Ghana. Thesis Paper 2016.

18. Lee PI, Lee CY, Huang LM, Chang MH. Longterm efficacy of recombinant hepatitis $B$ vaccine and risk of natural infection in infants born to mothers with hepatitis B e antigen. J Pediatr $1995 ; 126: 716-21$

19. Lin YC, Chang MH, Ni YH, Hsu HY, Chen DS. Long-term immunogenicity and efficacy of universal hepatitis B virus vaccination in Taiwan. J Infect Dis 2003;187:134-38.

20. El Mazahi MM, Maksoud HMA, Salam MA, Ali MA, El-Nawawy AN, Ahmad SM Long Term Immunity to Hepatitis B Vaccine Among a Sample of Secondary School Students in Damietta. Journal of American Science 10. 2014

21. Yazdanpanah B, Safari M, Yazdanpanah S Persistence of HBV vaccine's protection and response to hepatitis $\mathrm{B}$ booster immunization in 
5-to 7-year-old children in the Kohgiloyeh and Boyerahmad Province, Iran. Hepatitis monthly. 2010;10:17.

22. Hamid ATA, Said ZN Persistence of Protection to Hepatitis B Vaccine and Response to Booster Dose among Children and Adolescents in
Dakahleya -Egypt. EGYPTIAN JOURNAL OF IMMUNOLOGY. 2014;21:13-26.

23. Lu C-Y, Ni Y-H, Chiang B-L, Chen P-J, Chang $\mathrm{M}-\mathrm{H}$, Chang L-Y, et al Humoral and cellular immune responses to a hepatitis $\mathrm{B}$ vaccine booster 15-18 years after neonatal immunization. Journal of Infectious Diseases. 2008;197:1419-2

*Correspondence: Mohammad Monir Hossain, Junior Consultant, Department of Paediatric Neurology, Bangabandhu Sheikh Mujib Medical University, Dhaka, Bangladesh; e-mail: monir91@yahoo.com 